\title{
Docência em Gastronomia: uma revisão da literatura
}

\section{Teaching in Gastronomy: a literature review}

\author{
Tauane Carolina Parodi Be (tauane.be @iffarroupilha.edu.br) \\ Instituto Federal Farroupilha (IFFAR), Campus Jaguari \\ Vantoir Roberto Brancher (vantoir.brancher@iffarroupilha.edu.br) \\ Instituto Federal Farroupilha (IFFAR), Campus Jaguari
}

Resumo: Este trabalho consiste na apresentação do Estado da Arte realizado no intuito de encontrar artigos científicos e dissertações com enfoque na especificidade da Docência em Gastronomia, a fim de perceber o que tem sido pesquisado com relação à atuação docente na área. As investigações aconteceram com o jogo de palavras "trajetos formativos em Gastronomia", "saberes em Gastronomia", "Gastronomia" e "docência em Gastronomia" nos seguintes bancos de dados: Anped e Scielo, sendo que em ambas plataformas não foram encontrados resultados. Diante de tal dificuldade uma terceira tentativa ocorre ao migrar para a plataforma da CAPES e lançar a busca "docência em Gastronomia" houve um retorno de 361 arquivos, após a leitura de resumos e a seleção de pesquisas que objetivassem discutir a docência na área emergiram seis dissertações, que serão analisadas nesse artigo.

\section{Palavras-chave: Gastronomia; Docência; Formação.}

\begin{abstract}
:
This work consists of the presentation of the State of Art in order to find scientific articles and dissertations focusing on the specificity of Teaching in Gastronomy, in order to understand what has been researched in relation to the teaching activity in the area. The investigations took place with the play of words "training courses in Gastronomy", "knowledge in Gastronomy", "Gastronomy" and "teaching in Gastronomy" in the following data banks: Anped and Scielo, with no results found on both platforms. Faced with such difficulty a third attempt occurs when migrating to the CAPES platform and launch the search "teaching in Gastronomy" there was a return of 361 files, after reading summaries and the selection of research that aimed to discuss teaching in the area emerged six dissertations, which will be analyzed in this article.
\end{abstract}

Keywords: Gastronomy; Teaching; Formation.

\section{DOS CAMINHOS PERCORRIDOS}

Este estudo possui a intenção de apresentar o Estado da Arte, compreendendo a especificidade da Docência em Gastronomia, a fim de perceber o que tem sido pesquisado com relação à atuação docente na área. Ao realizar investigação no banco de dados da Anped com o jogo de palavras "Trajetos Formativos em Gastronomia", "Saberes em Gastronomia" e "Modelos Pedagógicos em Gastronomia" ou apenas "Gastronomia" não foi encontrado nenhum registro de trabalhos realizados. Sendo 
assim, seguindo na busca por pesquisas que tratassem de enfocar em Gastronomia e docência, ao digitar as palavras "Docência em Gastronomia" na mesma plataforma ainda não havia registro de trabalhos correspondentes à especificidade de assunto. A partir da inexistência de referências em tal site direcionou-se para o banco de dados da plataforma Scielo, na esperança de encontrar alguma pesquisa já realizada na área, sendo assim ao selecionar o filtro "Brasil" e digitar a busca "Docência em Gastronomia" não foram encontradas referências quanto a artigos ou periódicos abordando tal assunto, o mesmo ocorreu quando a busca limitou-se em "Trajetos Formativos em Gastronomia", "Saberes em Gastronomia", "Modelos Pedagógicos em Gastronomia" ou, simplesmente, "Gastronomia".

A partir de tal dificuldade foi acessada uma terceira plataforma de busca: o banco de teses e dissertações da CAPES, onde ao inserir a busca "Gastronomia" houve um retorno de 361 arquivos encontrados. Após ler os resumos e identificar quais os trabalhos que abordavam sobre o tema "Docência em Gastronomia" obteve-se uma redução deste número para um total de seis dissertações. Estas seis dissertações discutidas nesse artigo receberam o olhar dos autores principalmente no que se referem aos objetivos, metodologias e conclusões. Quanto às outras 355 dissertações os enfoques predominavam em outras direções como: hospitalidade e lazer, nutrição, Gastronomia como cultura, Gastronomia com olhar voltado para discentes, Gastronomia limitada a práticas de restaurantes e serviços de alimentações, marketing em Gastronomia, empreendedorismo e Gastronomia relacionada à questão antropológica da história da alimentação.

\section{MAPEAMENTO DAS PRODUÇÕES}

Após a leitura e análise dos resumos dos artigos mapeados, emergiram seis trabalhos (Quadro 1) preocupados em lançar um olhar para o docente gastrônomo. Os estudos em questão foram lidos pelos autores e observados principalmente no que tange os objetivos, as metodologias e as conclusões. Cabe mencionar que estes retratam sobre diferentes perspectivas o mesmo enfoque. Gastronomia.

Quadro 1 - Publicações do banco de dados da CAPES pesquisa sobre o docente em

\begin{tabular}{|c|c|l|c|}
\hline \multicolumn{4}{|c|}{ Tema: Docência em Gastronomia } \\
\hline Título & Autores & Cidade & Ano \\
\hline $\begin{array}{c}\text { Ensinando e } \\
\text { Aprendendo } \\
\text { Gastronomia: } \\
\text { percursos de } \\
\text { formação de } \\
\text { professores }\end{array}$ & $\begin{array}{c}\text { Márcia } \\
\text { Harumi } \\
\text { Miyazaki }\end{array}$ & Piracicaba & \multirow{2}{*}{2006} \\
$\begin{array}{c}\text { Entre Panelas, } \\
\text { Livros e Tradições: } \\
\text { as trajetórias de } \\
\text { formação do } \\
\text { professor de }\end{array}$ & $\begin{array}{c}\text { Beatriz de } \\
\text { Carvalho } \\
\text { Pinto }\end{array}$ & São Paulo & 2010 \\
\hline
\end{tabular}




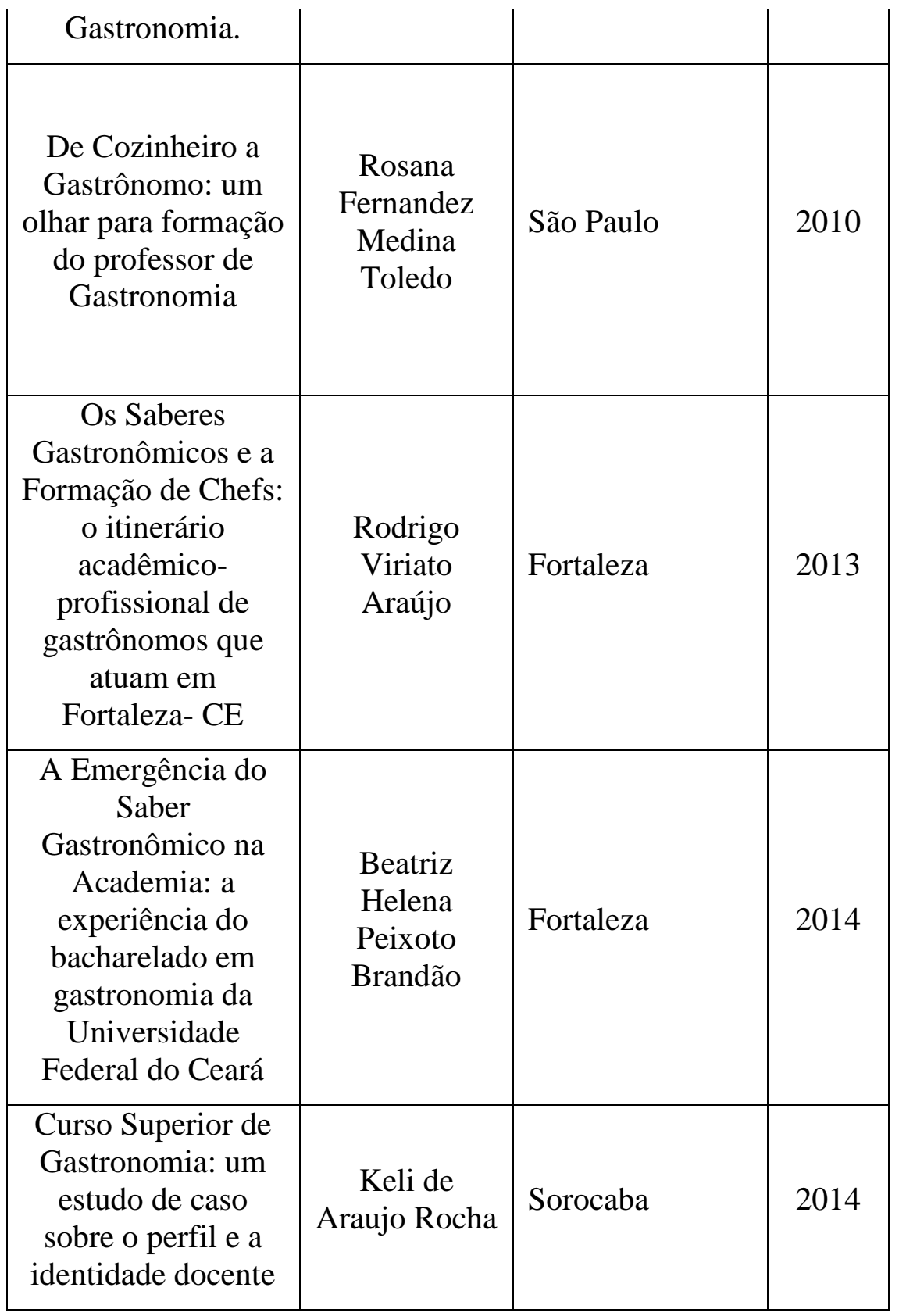

Fonte: da autora

Quanto à dissertação "Ensinando e Aprendendo Gastronomia: percursos de formação de professores", referente ao ano de 2006, trata-se de uma pesquisa apresentada para a obtenção de título de Mestre em Educação do Programa de PósGraduação em Educação da UNIMEP. O estudo objetiva conhecer quais os saberes que professores de prática, sem formação específica para docência, mobilizam para ensinar e a pesquisa tem enfoque em um curso superior de Tecnologia de Gastronomia no SENAC- Águas de São Pedro, no interior de São Paulo. A metodologia se dá da seguinte forma: a pesquisadora entrou em contato com alunos da $5^{\circ}$ turma do curso superior de Tecnologia em Gastronomia do SENAC, visando identificar dois "bons professores" de prática, sendo que os dois docentes que receberam mais votos foram convidados a participar de uma entrevista, a qual objetiva relatar as trajetórias de vida destes profissionais. 
A linha de escrita da autora é interessante, no ponto de vista que expressa historicamente todo o desenvolvimento do ensino superior de Gastronomia no Brasil, em um viés por vezes antropológico e filosófico. Além disso, procura estender o conhecimento de como se dá a criação do SENAC e a metodologia de ensino dentro da Instituição. A metodologia traz a confirmação de que os saberes de maior repetição em relação aos dois docentes são: saberes pessoais adquiridos pela família e ambiente; saberes de formação anterior, adquiridos na escola primária e secundária e saberes experienciais. Nas considerações finais a autora evidencia seu papel de "pioneirismo", ao relatar a inexistência de banco de dados preocupados em compreender a docência em Gastronomia mencionando que:

Pretendia-se, com esse estudo, conhecer que saberes os professores de prática que não têm formação específica para docência mobilizam para ensinar, visando contribuir para a reflexão e estudos da formação de professores de prática em Gastronomia, tendo em vista não haver identificado, no Brasil, nenhuma pesquisa a respeito de formação de professores de tal prática. (MIYAZAKI, 2004, p.98)

Além da questão da inexistência de pesquisas anteriores, salientado pela autora, é pertinente transcrever o último parágrafo, que finaliza as considerações desta, diante da premissa de que há uma espécie de sugestão intrínseca no entorno das palavras quanto à importância de futuras pesquisas, sobre diferentes enfoques, em relação à mesma problemática.

Considerando que a área de Gastronomia, como ensino superior, é relativamente nova no Brasil, há muitas possibilidades de continuidade desse trabalho: adentrar os laboratórios de cozinha e por meio da observação verificar como se materializa na prática, o discurso do professor, o que eles fazem? Como eles fazem? Perceber as nuanças nas falas dos alunos; investigar a prática dos demais professores, titulados ou não, com mais ou menos experiência docente; investigar as diferenças de práticas pedagógicas no ensino de Gastronomia, empregadas pelas instituições de renome na França e Estados Unidos, estabelecendo uma comparação com o Brasil; investigar como se dá a formação de professores de Gastronomia em outros países; fazer uma pesquisa com os egressos dos cursos que, atualmente, lecionam Gastronomia e como realizam essa prática; propor um programa para formação de professores de prática em Gastronomia. (MIYAZAKI, 2004, p.101) (grifo nosso)

Quanto ao que esse trecho nos sugere, é possível visualizar a dimensão da importância do estudo aqui proposto, além do enorme leque que nos falta assimilar e aprofundar, ao considerar a Gastronomia como uma área científica muito fértil. Quanto às frases em destaque na citação, estas emergem da intencionalidade de gerar reflexões acerca da importância da existência de um programa para formação de professores de Gastronomia, no sentido de compreender sobre quais alicerces se dá a atuação desses profissionais.

No que se refere à dissertação "Entre Panelas, Livros e Tradições: as trajetórias de formação do professor de Gastronomia", publicada no ano de 2010, trata-se de uma pesquisa apresentada ao Programa de Pós-Graduação em Educação - PPGE, da Universidade Nove de Julho - UNINOVE como requisito para obtenção de título de Mestre em Educação. O estudo teve como objetivo identificar os principais aspectos constituintes do processo de formação do professor que ministra aulas para o curso de Gastronomia da Faculdade Hotec. O procedimento metodológico foi pautado em 
pesquisas bibliográficas, levantamento de dados do INEP, 2010, análise de documentos e registros da instituição, entrevistas para Histórias de Vida e pesquisas de campo, com o corpo docente, através de observações in loco de aulas teóricas e práticas.

O trabalho apresenta no seu decorrer a questão da formação de professores de Gastronomia, sendo problematizada pela autora, além disso, o mapeamento de cursos de Gastronomia no Brasil e no mundo, a história da Hotec, a estrutura do curso de Gastronomia, o perfil do egresso e a história de vida de professores de Gastronomia. Apresenta metodologia com participação de oito professores atuantes no Curso Superior de Tecnologia em Gastronomia na Hotec, sendo possível, através das transcrições, identificar a despretensão destes, no momento da escolha profissional, em seguir carreira na docência. (RAMPIM, 2010, p.113) Porém, é necessário destacar o relato da autora quanto à sensação captada por esta durante as entrevistas através das vozes, dos gestos e da emoção, demonstrando um respectivo envolvimento, satisfação e "apaixonamento" pela docência no decorrer da prática destes profissionais.

Quanto às considerações finais são estabelecidos elos entre educação informal, relacionada à convivência em família; educação formal, relacionada a aspectos profissionais, educacionais e do mundo do trabalho; pesquisa, enquanto aproximação de teoria e prática; subjetividade, como fator de identidade docente, abrangendo cultura, reconhecimento e gênero; e a alteridade, constituinte da formação dos docentes envolvidos no estudo. Outro aspecto relevante na pesquisa são os dois últimos parágrafos, que se complementam, ao indicarem a importância da singularidade das narrativas em prol do coletivo e insinuarem a necessidade de continuidade de estudos na área.

Esta pesquisa indica que os aspectos constituintes da formação do docente são interligados entre si, de modo a se complementarem, não demonstrando, segundo as narrativas, um ser, isoladamente, mais relevante do que outro.

Não expusemos, de modo algum, a ideia de esgotarmos esta pesquisa e nem de apresentarmos nela verdades absolutas. Como dito anteriormente, a área de Gastronomia envolve um campo de saber milenar, mas que, ainda hoje, demonstra apresentar uma trajetória recente na academia (RAMPIM, 2010, p.132)

Em relação à dissertação "De Cozinheiro a Gastrônomo: um olhar para formação do professor de Gastronomia", também finalizada no ano de 2010, trata-se de um estudo apresentado para obtenção de Título de Mestre em Educação na Universidade Cidade de São Paulo - UNICID. O estudo tem como objetivo investigar os saberes que os professores mobilizam para formar gastrônomos e como os professores em Gastronomia tem acesso a esses saberes.

A pesquisa consiste em três capítulos sendo denominados pela autora como "olhares". Os olhares lançados nos capítulos são focados em: Gastronomia e seu surgimento no Brasil e no mundo, formação docente e matrizes pedagógicas. Quanto à metodologia, optou-se por entrevistas reflexivas direcionadas a quatro professores atuantes nos cursos superiores de Gastronomia, na cidade de São Paulo, sendo incluídos docentes com formação acadêmica pedagógica e professores sem tal formação. Um dos pontos que mais chamam atenção no decorrer da leitura é a relação que a autora procura realizar com a Gastronomia e a essencialidade de sua existência, destacando-a sobre vários enfoques: 
Cultural: visando a uma educação antropológica e analisando por que o homem se alimenta e qual a cultura que o rege. Alimentação em grupos individuais, em família;

Religioso: alimentos permitidos (ou não de acordo com a crença, com a fé, com rituais);

Político: como é o caso dos alimentos orgânicos: consumo por crer que esse tipo de alimento salvará o planeta;

Filosófico: vão muito além do aspecto religioso, alimentos que fazem bem ao espírito;

Econômico: ditado pela situação financeira propriamente dita;

Fisiológico: comer o que faz bem ao organismo, pensar em vitaminas e proteínas. (TOLEDO, 2010, p.24)

Tal relação detém uma possibilidade de aprofundamento em pesquisas futuras na intencionalidade de destacar a multidimensionalidade de aspectos que a Gastronomia e a história da alimentação, sobre uma visão antropológica, exercem em um panorama amplificado. $\mathrm{O}$ instrumento de pesquisa, materializado em entrevistas reflexivas através de perguntas abertas, objetivou identificar aspectos referentes à experiência profissional. Após as entrevistas individuais, a autora destaca certo desnivelamento quanto à duração destas, onde um parece ter sido muito mais rápido em relação aos outros:

Como o tempo médio das entrevistas foi 90 minutos, me chamou muito a atenção à entrevista feita em vinte minutos. Então diante disso, refiz a entrevista, depois de uma semana, solicitando ao entrevistado que falasse um pouco mais sobre sua atuação docente, de uma forma mais livre, sem direcioná-lo com perguntas. O resultado não acrescentou mais informações e a fala não passou de 20 minutos. A fala recorrente foi dizer que não escolheu ser docente e que essa profissão lhe apareceu por acaso. (TOLEDO, 2010, p.54)

É possível, portanto, compreender que as singularidades a serem discutidas em relação à docência jamais seguem um padrão específico e as vivências, inevitavelmente, exercem influência na possibilidade de identificação ou não com a profissão, ao longo do tempo. Uma das contrastantes falas, que comprova as diferentes perspectivas inerentes ao contexto individual da docência, advém de um dos entrevistados, que diz: "Eu nasci professor. Eu nasci professor porque a gente imita o professor, eu tive mãe professora, tia professora. O meu pedigree é de professor." (TOLEDO, 2010, p. 62). Nesse sentido, é possível visualizar a docência como uma conquista individualizada, carregada de significados e de subjetividades. Ainda em relação às transcrições, um dos entrevistados relaciona seu trabalho com a arte, sedução e paixão, ao relatar que:

Eu sou sedutor. Eu seduzo os meus alunos. Eu uso essas qualidades que eu tenho para seduzir o aluno. $O$ meu interesse não é só cumprir o cronograma que eu estabeleço no semestre. É óbvio que eu vou cumprir aquilo tudo. Eu gosto de trabalhar numa escola como a Unitec, que tem um nível baixo de alunos carentes. Porque eu sinto que posso contribuir mais. Eu procuro de certa forma passar para eles valores de vida, conhecimento que tenho de viagens, de um monte de coisas que eu vi na vida. Então a aula se torna interessante porque você vai cortando a monotonia da disciplina com assuntos que você vai trazendo e que vai chamado a atenção do aluno e vai despertando o aluno para outras coisas. Tive uma homenagem na Universidade e uma aluna chegou para mim e disse: - Professor quando alguém muda sua vida é muito importante falar para essa pessoa. E você 
mudou a minha vida. Hoje em dia eu tô fazendo um curso de Marketing por causa das suas aulas-. E esse tipo de depoimento já aconteceu comigo várias vezes. De o aluno se apaixonar por aquele conteúdo, que isso faz parte de todo esse processo de sedução que eu faço com a classe. E esse processo eu posso exercitar melhor nas aulas de Gastronomia. Sou muito teatral na sala de aula e os alunos vibram. O mais importante é você estimular o aluno e fazer ele ir atrás. Eu converso muito com os alunos. Coisa que toda faculdade que eu fiz eu nunca tive isso. Eram professores que dominavam os respectivos conteúdos, mas eram extremamente frios. E eu quando dou uma aula me esforço demais e o aluno percebe isso. Há uma troca muito grande e não há dinheiro que pague. (TOLEDO, 2010, p.70) (grifo nosso)

A riqueza interiorizada nesse depoimento enfatiza diversas categorias que sugerem, sobretudo, um amor e uma identificação com a docência. A intencionalidade de criar vínculos, de disseminar histórias, de estimular o aprendizado de maneira singular e concreta, a visível entrega e a noção de doação presente nas palavras do entrevistado remetem à profundidade de vivências e experiências que só uma docência pode carregar. É uma espécie de tradução capaz de derrubar certas barreiras de uma complexidade na carreira e disseminar a simplicidade de uma paixão e do prazer pela possibilidade de ensinar.

Ainda em relação a essa dissertação podemos identificar, assim como nas anteriores, a necessidade expressa pela autora de mais pesquisas na área:

\begin{abstract}
(...) pelo fato de os cursos superiores de Gastronomia serem recentes no Brasil, há grandes possibilidades de continuidade desse trabalho, buscando conhecer como o discurso docente, dentro dos laboratórios gastronômicos e salas de aulas, se materializam na prática. Quais as diferenças de atuação de professores titulados e dos não titulados. Como ocorre a docência de Gastronomia em países europeus, onde a Gastronomia já galgou espaços renomados, em comparação ao Brasil. Como se dá a formação de professores de Gastronomia em outros países. Na Argentina, por exemplo, há um curso superior de licenciatura em Gastronomia, oferecido pela Universidad Argentina de la Empresa (UADE), dentro da Faculdade de Comunicação e Desenho. (TOLEDO, 2010, p.73-74).
\end{abstract}

É a partir dessa consideração de Toledo (2010) que seguimos na linha do tempo das pesquisas realizadas sobre docência em Gastronomia em questão, direcionando um olhar para a dissertação "Os Saberes Gastronômicos e a Formação de Chefs: o itinerário acadêmico-profissional de gastrônomos que atuam em Fortaleza- CE." Trata-se de uma dissertação do Programa de Pós-graduação em Educação Brasileira da Faculdade de Educação da Universidade Federal do Ceará, como requisito para obtenção do grau de Mestre em Educação, realizada no ano de 2013, objetivando abordar o percurso acadêmico, profissional e pessoal de profissionais atuantes no campo da Gastronomia, na cidade de Fortaleza. A metodologia baseia-se em entrevistar um grupo heterogêneo de profissionais ligados à Gastronomia, dentre eles o professor de Gastronomia.

Quanto à entrevista relacionada ao objetivo desse artigo, direcionada à professora de Gastronomia, pode-se destacar a alusão que a entrevistada faz à sua história de vida e ao poder do alimento de entrelaçar histórias. Após relatar que teria sido adotada por uma tia com condições financeiras melhores, a professora ainda sugere que o motivo de ter investido na carreira da Gastronomia está na alegria que a mesa lhe traz, desde a infância: 
De alegria, satisfação, festa. Porque toda vez que se sentava à mesa, apesar de eu ser filha adotiva, na casa da minha tia nunca estive só (...) Então papai sentava à mesa. Estava todo mundo sentado, mas só se comia quando ele chegava. Ele tirava primeiro uma colher de arroz. Aí era festa, todo mundo se servia, era muita conversa, era muito família. Mesa, para mim, é uma transmissão de amor muito grande porque a gente recebia muito amor através da mesa. Assim, traduzindo tudo o que eu gostava estava na mesa. (ARAÚJO, 2013, p. 55)

É possível observar, mais uma vez, a influência que as vivências exercem na escolha de uma profissão, ainda mais em uma carreira dotada de memórias e ressignificações como a Gastronomia. Porém, no decorrer do texto é relatado que a entrevistada, professora de Gastronomia, na realidade é apresentadora de um programa na televisão, que ensina a produção de receitas específicas e, segundo o autor, quando questionada a respeito das distintas formações hoje no ramo da Gastronomia não soube diferenciá-las nem quanto ao tempo de duração das modalidades, nem quanto aos modelos de ensino. Sendo assim, se faz necessário relatar que, de certa forma, acabou ocorrendo uma frustração imediata quanto à expectativa diante de tanta criatividade no decorrer da escrita e a consequente abordagem realizada de maneira tão minimizada em relação à docência. Considerando a importância de tal profissão, o autor poderia ter explorado sob outra perspectiva, com um olhar mais amplo, voltado para o docente em Gastronomia de Instituições de ensino.

Diante disso, passamos para a análise da dissertação "A Emergência do Saber Gastronômico na Academia: a experiência do bacharelado em gastronomia da Universidade Federal do Ceará", referente ao ano de 2014, trata-se de um estudo apresentado ao Programa de Pós-Graduação em Educação Brasileira da Faculdade de Educação da Universidade Federal do Ceará - FACED/UFC, para obtenção do título de Mestre em Educação Brasileira. O objetivo geral está centrado em problematizar a formação do bacharel em Gastronomia pela Universidade Federal do Ceará através da análise do Projeto Político-pedagógico e do discurso de gestores, docentes e discentes sobre as vivências e as impressões do curso.

A metodologia é dividida em três etapas: análise sócia histórica; análise formal/discursiva e interpretação/reinterpretação. Em relação às duas primeiras etapas a pesquisadora realizou um "passeio pelas paisagens que marcaram a trajetória dos atores do estudo- tanto entrevistados (gestores, professores e alunos), como da pesquisadora." (BRANDAO, 2014, p.17) A pesquisa de campo, através de entrevistas, foi realizada na UFC em diversos lugares: Pró-reitora de Graduação, Coordenação do Curso de Gastronomia, corredores do ICA, cantina do Curso de Economia Doméstica, diferentes cenários da Faculdade de Educação, pátio e sala de jantar da Casa de Cultura Italiana, Centro de Humanidades, residência de alunos e da pesquisadora. A última etapa aconteceu através da análise formal e sócio histórica, ressignificando as representações dos envolvidos na pesquisa.

Uma das problematizações realizadas pela autora é a questão da teoria e da prática dentro da Gastronomia, o qual apesar de ser um campo de atuação muito embasado na prática necessita de uma sintonia entre a teoria e a prática, no intuito de consolidar uma aprendizagem ampla, sendo que:

Não se pode negar que a coesão entre a prática e teoria, embora difícil de concretizar, sempre foi indispensável e desejada pelos gestores que formaram 
as bases desse curso. Esse encontro traduz, portanto, o nascimento de alguns imperativos: trazer o cozinheiro ao cotidiano acadêmico, introduzindo-o às exigências técnicas e formais que envolvem a docência no ensino superior, apresentando-o às condições institucionais universitárias; inserir o profissional acadêmico na lógica dessa Gastronomia extremamente física, dinâmica e pautada por signos socioculturais e mercadológicos; ressignificar a síntese desse intercâmbio, valorizando as habilidades e competências pessoais de cada docente, alimentando outras experiências dentro e fora da Universidade; e, finalmente, aproximar seus códigos culturais, amenizando a distância entre eles, de forma a consolidar, ao longo dos anos de prática, um habitus acadêmico do professor em Gastronomia. (BRANDAO, 2014, p.61)

Esse habitus acadêmico do professor de Gastronomia é fruto de uma fusão de diversos elementos interdependentes diretamente ligados aos saberes, às vivências e aos trajetos. Estes elos formam uma espécie de delineamento da identidade e das práticas de um professor da área ao ampliar a capacidade de repassar o conhecimento, mesmo que fragmentado, de forma inteira, relacionando-o com aspectos do mundo do trabalho, da história e da contextualização. É o "saber ensinar" mencionado por Tardif (2008, p.187):

(...) dizer que alguém sabe ensinar significa menos dizer que ela possui "em si mesmo", em seu cérebro, em sua memória, em seus "conhecimentos anteriores", um saber no sentido tradicional de uma teoria ou de uma representação que implica um certo grau de certeza, do que dizer que sua ação pedagógica é conforme a certas normas e a certas expectativas, as quais podem ser fixadas por várias instâncias (a instituição, os pares, os alunos, os pais) ou, na maioria das vezes, por todas essas instâncias ao mesmo tempo. Isso provoca invariavelmente tensões e um conflito de interpretações da definição normativa do "saber ensinar".

A partir da compreensão deste universo do "saber ensinar" que tentamos nos aproximar quando bifurcamos o olhar voltado tanto para a docência quanto para a Gastronomia. Dentro dessa perspectiva, a autora compara os alunos e os professores a porta-vozes de um saber acadêmico:

Os alunos e professores são porta-vozes de um saber acadêmico que deve ser compartilhado, bem como devem perceber a riqueza do saber decorrente desse mercado. A resistência de profissionais que já pertenciam a este mundo em relação a essa nova gama de profissionais que se forma no ano de 2013 é um sinal de que existe sim um processo transformador em trânsito. Da mesma forma, alguma aceitação desse novo conhecimento por essa "velha guarda gastronômica" consolida os pequenos passos dessa mudança positiva. Como relacionou um dos colegas, vive-se um momento de transição entre a Gastronomia cearense de antes e de depois do bacharelado. (....) As traduções de alunos e professores sobre o objeto Gastronomia provam o longo alcance dessa mudança de percepção: concebe-se que, do campo à mesa, existe uma longa trajetória de histórias, as quais somente começaram a ser percebidas nesse cenário universitário. Essas "micro-histórias" encontram, na preparação, o ápice de uma rede de conexões que ligam muitas vidas. A internalização dessa consciência e dessa atitude profissional, para os alunos e professores, é sinal de muitas outras transformações que estão por vir. Por meio dessas incorporações, o bacharelado passa a afirmar sua contribuição científica dentro de sua função social. (BRANDAO, 2014, p.111-112)

Acerca disso, podemos vincular a função social que um curso de Gastronomia exerce dentro de um viés de valorização cultural, regional, individual e coletivo. A fala de Brandao (2014) configura-se como um incentivo à oportunidade que um curso de 
Gastronomia projeta através da tradução de histórias, trajetórias e consolidação de aprendizados e memórias, sendo assim, no final de suas escritas a autora deixa aberto um espaço para mais diálogos acerca do tema, com enfoque na UFC: "Agora, fica a expectativa sobre aqueles que já escrevem e sobre os muitos que ainda escreverão as demais linhas do Bacharelado em Gastronomia da Universidade Federal do Ceará. Está apenas começando" Brandao (2014, p.117).

A última dissertação a ser discutida aqui, escrita também no ano de 2014, apresenta o título "Curso Superior de Gastronomia: um estudo de caso sobre o perfil e a identidade docente". Trata-se de um estudo apresentado para o Programa de PósGraduação em Educação da Universidade de Sorocaba, como exigência para obtenção de título de Mestre em Educação. O objetivo do trabalho é realizar um estudo de caso no intuito de conhecer a trajetória profissional e identificar o perfil e a identidade profissional dos docentes do ensino superior em Gastronomia, analisando o cenário em que atuam, sua historicidade e a percepção de si mesmos. A metodologia está centrada na realização de uma pesquisa quantitativa considerando as informações dos docentes na plataforma "Lattes", e uma pesquisa qualitativa, com questionários individuais com professores que ministram aulas práticas no curso de Tecnologia em Gastronomia de uma instituição de ensino superior do Estado de São Paulo.

Baseando-se nas escritas de Pimenta e Anastasiou (2002) a autora problematiza a questão da profissionalidade docente, ao retratar um quadro crítico e frequente atual brasileiro: do professor sem formação pedagógica. Tal realidade pode ser vista, principalmente, em cursos culturalmente pautados na prática, como a Gastronomia, visando o preparo e a elaboração de receitas. As palavras de Pimenta e Anastasiou (2002), transcritas por Rocha (2014, p.69-70) a respeito da formação pedagógica alarmam e evidenciam essa realidade:

\begin{abstract}
(...) há um certo consenso de que a docência no ensino superior não requer formação pedagógica; requer apenas conhecimentos exclusivos sobre a área específica em que são ministradas as aulas. Isso gera descomprometimento do professor, que não se responsabiliza pelo processo de ensino e aprendizagem por desconhecer sua participação nesse processo. $\mathrm{O}$ docente, em geral, trata o magistério aqui como uma segunda opção e não outorga quase nenhuma importância à sua atuação enquanto profissional.
\end{abstract}

Além de destacar a questão da formação pedagógica Rocha $(2014$, p.84) defende noções de profissionalização docente e atenta para a dificuldade que o professor enfrenta em receber incentivo da Instituição para desenvolver e aprimorar sua base teórica. Enfatizando, portanto, que a autonomia docente se dá até certo ponto de um discurso contraditório "afinal o professor universitário deve trabalhar seu conteúdo a partir de um curriculum definido previamente e da forma como foi preestabelecido, obedecendo parâmetros moldados segundo a sociedade capitalista que regula o ensino superior".

Após realizar um embasamento teórico consistente e esclarecedor Rocha (2014) apresenta a metodologia da pesquisa: uma pesquisa de campo realizada em uma Instituição de Ensino Superior, na região de Sorocaba, São Paulo, nos meses de abril e maio de 2014. Constatou que existem 24 docentes na Gastronomia, sendo seis deles vinculados às aulas práticas na área e convidados a participar da pesquisa. Em um primeiro momento houve a pesquisa do Lattes dos sujeitos e posteriormente estes responderam a um questionário individual com questões reflexivas incluindo: atuação 
docente, carga horária, experiência, atividades docentes e não docentes e questões abertas sobre identidade docente, tanto na Gastronomia como na docência e seu olhar sobre essa trajetória enquanto relevância, identidade e influência na formação. As respostas dos questionários são apresentadas em tópicos, a partir de esquemas em percentagem, quadros, tabelas e planilhas, na sequência da dissertação.

A conclusão da autora em relação aos saberes que professores mobilizam para ensinar inclui os saberes adquiridos ao longo da vida, os experienciais, os acadêmicos e os cursos de aperfeiçoamento, além dos construídos em sala de aula, com a troca de saberes com os alunos. Apesar de conseguir expressar e explorar de maneira satisfatória a temática, apresentando resultados a partir da coleta de dados de maneira eficaz, é preciso ressaltar que os dados obtidos da pesquisa poderiam ter sido mais amplos se a investigação incluísse uma diferente metodologia, a partir das narrativas de histórias de vida, como as entrevistas semiestruturadas, por exemplo.

Ainda em relação às considerações finais, destaca-se, assim como em outras dissertações mencionadas, a preocupação e a necessidade de mais estudos em tal área, caracterizada por ser tão recente e com pouco embasamento científico e acadêmico, onde: “(...) a Gastronomia prescinde de uma identidade própria, o que se reflete em seus profissionais, que ainda carecem de estudos sobre seu perfil". (ROCHA, 2014, p.141). Sendo assim, fica nítida a complexidade e individualidade de características do ensino em qualquer área, inclusive em uma área de viés singular, como a Gastronomia.

\section{CONSIDERAÇÕES FINAIS}

Cabe mencionar a escassez de trabalhos na área e a intensa dificuldade enfrentada pelos pesquisadores em encontrar, virtualmente, pesquisas com o intuito de compreender como se dá a docência na área da Gastronomia. Quanto aos trabalhos encontrados é visível que se trata de uma preocupação recente, considerando que as datas de publicações destes se limitam do ano de 2006 ao ano de 2014. Além disso, é preciso considerar que posterior à primeira publicação somente após quatro anos é que houve publicação de outra escrita na mesma temática. Ainda em relação à particularidade das datas cabe concluir que há uma nulidade de publicação desde 2014, ou seja, sugere-se que há quatro anos não se pensa na figura do docente gastrônomo, ao menos no que se refere a publicações disponíveis na Plataforma da CAPES, Scielo e Anped.

Outro aspecto considerável em relação ao balanço geral das pesquisas discutidas é o fato de que estas emergem de regiões específicas nas quais, possivelmente, o ensino de Gastronomia apresentou maior proporção ou visibilidade. A região que detêm maior ênfase em pesquisas de Gastronomia se limita ao estado de São Paulo, seguida pela cidade de Fortaleza, no estado do Ceará. Considerando tais colocações, vale reafirmar a necessidade de compreender a Gastronomia como uma área rica de informações, que carecem de desbravamento em nível científico, sobre diversas dimensões e perspectivas. Convém, entretanto, ressaltar o significativo papel que estas dissertações têm, ao traçar um importante início na empreitada de compreender a docência em Gastronomia como uma área multifacetada, que vai muito além das panelas, sobressaindo o universo da prática em cozinha e enriquecendo o universo científico sobre diversos significados, relatos de vivências, sobretudo, nutrindo expectativas em um futuro com numerosas publicações que compreendam e valorizem a figura do professor gastrônomo. 


\section{CITAÇÕES}

ARAUJO, Rodrigo Viriato. Os saberes gastronômicos e a formação de chefs: o itinerário acadêmico-profissional de gastrônomos que atuam em Fortaleza- CE. 2013.

Disponível em

https://sucupira.capes.gov.br/sucupira/public/consultas/coleta/trabalhoConclusao/vie wTrabalhoConclusao.jsf?popup=true\&id trabalho=89799> Acesso em 21/03/2018 às 10:00

BRANDAO, Beatriz Helena Peixoto. A emergência do saber gastronômico na academia: a experiência do bacharelado em gastronomia da Universidade Federal do Ceará. 2014. Disponível em < https://sucupira.capes.gov.br/sucupira/public/consultas/coleta/trabalhoConclusao/vie wTrabalhoConclusao.jsf?popup $=$ true\&id trabalho=148888> Acesso em 22/03/2018 às 10:00.

MIYAZAKI, Márcia Harumi. Ensinando e Aprendendo Gastronomia: Percursos de Formação de Professores. 2006. Disponível em < https://www.unimep.br/phpg/bibdig/pdfs/2006/IUAOWFOVEOIC.pdf> Acesso em: 21/03/2018 às 12:30.

PIMENTA, Selma Garrido; ANASTASIOU, Léa das Graças Camargos. Docência no ensino superior. Cortez editora. 2002

RAMPIM, Beatriz de Carvalho Pinto. Entre panelas, livros e tradições: as trajetórias de formação do professor de Gastronomia. 2010. Disponível em < http://bibliotecatede.uninove.br/handle/tede/447> Acesso em 21/03/2018 às 10:00.

ROCHA, Keli de Araujo. Curso Superior de Gastronomia: um estudo de caso sobre o perfil e a identidade docente. 2014. Disponível em < https://sucupira.capes.gov.br/sucupira/public/consultas/coleta/trabalhoConclusao/vie wTrabalhoConclusao.jsf?popup $=$ true\&id trabalho=1978314> Acesso em 22/03/2018 às 13:00.

TARDIF, Maurice. Saberes docentes e formação profissional. $14^{\circ}$ ed. Editora Vozes Limitada, 2008.

TOLEDO, Rosana Fernandez Medina. De Cozinheiro a Gastrônomo: um olhar para a formação do professor de gastronomia. 2010. Disponível em < http://arquivos.cruzeirodosuleducacional.edu.br/principal/old/mestrado_educacao/di ssertacoes/2010/dissertacao_2010_Rosana_Toledo.pdf> Acesso em 22/03/2018 às $14: 30$. 